\title{
Air transportation, population density and temperature predict the spread of COVID-19 in Brazil
}

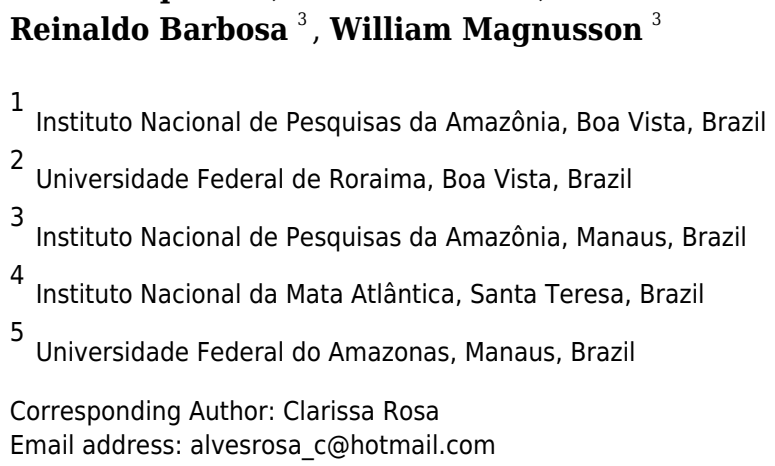

There is evidence that COVID-19, the disease caused by the betacoronavirus SARS-CoV-2, is sensitive to environmental conditions. However, such conditions often correlate with demographic and socioeconomic factors at larger spatial extents, which could confound this inference. We evaluated the effect of meteorological conditions (temperature, solar radiation, air humidity and precipitation) on 292 daily records of cumulative number of confirmed COVID-19 cases across the 27 Brazilian capital cities during the first month of the outbreak, while controlling for an indicator of the number of tests, the number of arriving flights, population density, proportion of elderly people and average income. Apart from increasing with time, the number of confirmed cases was mainly related to the number of arriving flights and population density, increasing with both factors. However, after accounting for these effects, the disease was shown to be temperature sensitive: there were more cases in colder cities and days, and cases accumulated faster at lower temperatures. Our best estimate indicates that a one Celsius degree increase in temperature has been associated with a decrease in confirmed cases of eight percent. The quality of the data and unknowns limit the analysis, but the study reveals an urgent need to understand more about the environmental sensitivity of the disease to predict demands on health services in different regions and seasons. 
1 Air transportation, population density and temperature predict the 2 spread of COVID-19 in Brazil

3

4

5

6

7

8 9

Pedro Aurélio Costa Lima Pequeno ${ }^{1}$, Bruna Naissinger Mendel ${ }^{2}$, Clarissa Alves da Rosa $^{3}$, Mariane Bosholn ${ }^{1}$, Jorge Luiz Pereira Souza ${ }^{4}$, Fabricio Beggiato Baccaro ${ }^{5}$, Reinaldo Imbrozio Barbosa ${ }^{1}$, William E. Magnusson ${ }^{3}$

${ }^{1}$ Núcleo de Pesquisas de Roraima, Instituto Nacional de Pesquisas da Amazônia, Boa Vista, Roraima, Brazil

2 Programa de Pós-graduação em Recursos Naturais, Universidade Federal de Roraima, Boa Vista, Roraima, Brazil

${ }^{3}$ Coordenação de Biodiversidade, Instituto Nacional de Pesquisas da Amazônia, Manaus, Amazonas, Brazil

${ }^{4}$ Instituto Nacional da Mata Atlântica, Santa Teresa, Espírito Santo, Brazil

${ }^{5}$ Departamento de Biologia, Universidade Federal do Amazonas, Manaus, Amazonas, Brazil.

Corresponding Author: Clarissa Alves da Rosa

Av. André Araújo, 2936, Manaus, Amazonas, CEP 69067-375, Brazil

Email address: rosacla.eco@gmail.com

\section{Abstract}

There is evidence that COVID-19, the disease caused by the betacoronavirus SARSCoV-2, is sensitive to environmental conditions. However, such conditions often correlate with demographic and socioeconomic factors at larger spatial extents, which could confound this inference. We evaluated the effect of meteorological conditions (temperature, solar radiation, air humidity and precipitation) on 292 daily records of cumulative number of confirmed COVID-19 cases across the 27 Brazilian capital cities during the first month of the outbreak, while controlling for an indicator of the number of tests, the number of arriving flights, population density, proportion of elderly people and average income. Apart from increasing with time, the number of confirmed cases was mainly related to the number of arriving flights and population density, increasing with both factors. However, after accounting for these effects, the disease was shown to be temperature sensitive: there were more cases in colder cities and days, and cases accumulated faster at lower temperatures. Our best estimate indicates that a one Celsius degree increase in temperature has been associated with a decrease in confirmed cases of eight percent. The quality of the data and unknowns limit the analysis, but the study reveals an urgent need to understand more about the environmental sensitivity of the disease to predict demands on health services in different regions and seasons. 
41

42

43

44

45

46

47

48

49

50

51

52

53

54

55

56

57

58

59

60

61

62

63

64

65

66

67

68

69

70

71

72

73

74

75

76

77

78

79

80

\section{Introduction}

The disease COVID-19, caused by the betacoronavirus SARS-CoV-2, has caused panic throughout the world by overwhelming medical services in many countries, leading to deaths that might have been avoided if patients had access to intensive-care units (ICUs). This has led to an unprecedented collaboration within and among countries to slow the spread of the disease, principally using social distancing (Ebrahim et al., 2020; Wilder-Smith \& Freedman, 2020). While it is not clear how much present policies will reduce overall infection rates by SARS-CoV-2, there is consensus that slowing the spread of the disease will save lives by tailoring patient demands to the capacity of health systems (Ferguson et al., 2020; Walker et al., 2020).

The strategies of social isolation applied in countries on all continents have allowed time for authorities to undertake interventions to strengthen their health systems, and one of the main actions is to estimate the number of cases of COVID-19 in each region (Anderson et al., 2020; Walker et al., 2020). This information is essential to scale the number of ICUs to the number of critically ill patients who normally require supportive lung ventilation (Xu et al., 2020). Brazil has a large per capita number of ICUs in comparison with Europe, but those units are not evenly spread among regions, with more ICUs per capita in southern states than in northern regions, leaving many Brazilians at large distances from the nearest ICU (Rhodes \& Moreno, 2012). Moreover, the large demographic and socioeconomic discrepancies in the country create significant variation in susceptibility to infectious diseases (Barreto et al., 2011).

One of the problems in predicting the demand for hospital services is that the disease is new so that its behavior is still poorly understood, and the virus may be evolving rapidly (Zhao et al., 2004; Yang et al., 2020; Morais Jr. et al, 2020, unpublished data). Therefore, models developed in one country may give poor predictions in another. Habitat-specificity modeling suggests that SARS-CoV-2 spread may be related to environmental conditions, especially temperature and humidity (Sajadi et al., 2020; Wang et al., 2020). Further, at the host level, there is circumstantial evidence that COVID-19 is related to shortage of vitamin $\mathrm{D}$, which could result from limited exposition to solar radiation (Grant et al., 2020). Indeed, it has been suggested that solar radiation might deactivate the virus (Poole, 2020). Although preliminary, these results provide a plethora of mechanistic processes linking weather and virus spread that need to be better understood.

Brazil is one of the largest countries in the world, spanning both hemispheres, with latitudes varying from $5^{\circ} \mathrm{N}$ to $33^{\circ} \mathrm{S}$. This means that climatic conditions vary greatly and simple models that do not take into account the possible environmental sensitivity of COVID-19 might not be adequate to predict when and where there will be the greatest demand for health services in Brazil (Fig. 1). One difficulty in quantifying this sensitivity is that climate is likely to correlate with demographic and socioeconomic factors across 
81 larger spatial extents. Thus, environmental effects could be confounded unless risk 82 factors for viral spread are taken into account, such as population density, transport 83 connectivity and economic status (Poole, 2020; Wang et al., 2020; Ribeiro et al., 2020, 84 unpublished data).

85 In an attempt to determine whether environmental variables have significant 86 effects on the propagation of COVID-19, we modeled the daily cumulative number of 87 confirmed cases among Brazilian capital cities in relation to meteorological variables 88 during the first month of the disease in the country, while controlling for several demographic and socioeconomic factors. We used only capital cities because they are presently the only reliable sources of COVID-19 cases and represent much of the climatic variation within Brazil. Data on connectivity and frequency of cases is not presently adequate to model the spread of the disease at the municipal level, but this should be available in the future and can be used to test our hypotheses.

\section{Materials \& Methods}

We obtained daily cumulative counts of confirmed cases of COVID-19 for each of the 27 Brazilian state capital cities, as reported by State Health Secretaries and compiled by volunteers (Supplementary Material, Table S1; Secretarias de Saúde das Unidades Federativas, 2020). We focused on the month since the first confirmed case, from February 26 to March 26, 2020, for which there were 292 reports on daily counts across cities.

We considered several potential predictors of the number of confirmed cases. First, it was important to account for the number of tests for COVID-19, as performing more tests tends to reveal more positive cases (Roser et al., 2020). The Brazilian Government has not been systematically reporting the number of performed tests, but has recommended testing of all suspected patients with severe symptoms, and the Ministry of Health reported the number of suspected cases per state until March 18, 2020. Therefore, we used the number of suspected cases per state on that date as a proxy for the number of tests, under the reasonable assumption that states with more suspected cases performed more tests.

Further, we considered the following predictors: (1) time in days, to account for the exponential growth in case numbers during this period (Fig. 2); (2) number of arriving flights in the city's metropolitan area in 2020 , as airline connections can facilitate the spread of the virus (Ribeiro et al., 2020, unpublished data); (3) city population density, to account for facilitation of transmission under higher densities (Poole, 2020); (4) proportion of elderly people ( $\geq 60$ years old) in the population, assuming that the elderly may be more likely to show severe symptoms of SARS-CoV-2 and, thus, to be diagnosed with COVID-19; (5) citizen mean income, which may affect the likelihood of people being infected by the virus, e.g. due to limited access to basic sanitation or limited social isolation capabilities; (6) and the following meteorological variables: mean daily temperature $\left({ }^{\circ} \mathrm{C}\right)$, mean daily solar 
121 radiation $\left(\mathrm{kJ} / \mathrm{m}^{2}\right)$, mean daily relative humidity $(\%)$ and mean daily precipitation $(\mathrm{mm})$. The 122 number of suspected cases and socioeconomic variables only varied across cities, whereas meteorological variables varied both between and within cities.

Data on population density, the elderly and income were obtained for the last quarter of 2019 from the Brazilian Institute for Geography and Statistics (IBGE), which samples Brazilian households quarterly for socioeconomic indicators (SIDRA, 2020) (Supplementary Material, Table S2). Flight data were obtained from the current statistical annuary of the Brazilian Agency for Civilian Aviation (ANAC) (Supplementary Material, Table S3; ANAC, 2020). Hourly meteorological data were obtained from the automatic stations maintained by the Brazilian Institute for Meteorology (INMET) in the capital cities (Supplementary Material, Table S4; INMET, 2020).

We investigated the response of case counts to putative predictors using a Generalized Linear Mixed Model (GLMM) assuming Poisson-distributed errors and log link, and using capital-city identity as a random factor to account for autocorrelated errors within cities. This formulation induces a compound symmetry correlation structure on residuals within cities, which is mathematically equivalent to that of classical, "repeated measures" linear models (Zuur et al., 2009). The numbers of suspected cases and arriving flights were log-transformed to account for their highly skewed distributions, and all predictors were scaled to zero mean and unit standard deviation to facilitate parameter estimation. Consequently, estimated coefficients were scaled, thus providing a measure of predictor relative importance. Specifically, assuming a log link, a change of one unit in the scaled predictor implies a mean percent change of [exp(coefficient/SD) - 1)] $\times 100$ in the number of confirmed cases, where "coefficient" and "SD" are the predictor's model coefficient and standard deviation, respectively.

We considered time lags in the effect of meteorological conditions. Incubation time of COVID-19 averages five days (Lauer et al., 2020), and case confirmation in Brazil has taken from several days to two weeks due to overload of test laboratories. Therefore, the time between infection and case confirmation is likely to be longer than a week. Accordingly, we considered a set of models including all predictors but varying in the number of days meteorological predictors were lagged relative to case counts, ranging from seven to 30 days with daily steps. Then, models were compared with Akaike's Information Criterion (AIC), a standard measure of model relative support, and the model with the lowest AIC was judged as the most supported.

Precipitation time series had missing intervals for some capital cities. Therefore, we performed two versions of the above analysis: one including all predictors but excluding days for which precipitation was lacking $(n=269)$ and another one excluding precipitation as predictor and using all counts of confirmed COVID-19 cases ( $n=292)$. Because both analyses produced largely similar results, with precipitation having a negligible model coefficient (Supplementary Material, Figs. S1 and S2, Table S5), we present the analysis using the larger sample. 
161

162

163

164

165

166

167

168

169

170

171

172

173

174

175

176

177

178

179

180

181

182

183

184

185

186

187

188

189

190

191

192

193

194

195

196

197

198

199

200

Lastly, we considered possible interactions between time and other predictors, assuming some factors could accelerate the temporal increase in number of confirmed cases. By definition, GLMMs assuming a log link implicitly account for interactive effects to some degree, as log-linear models imply multiplicative effects. Still, we ran a separate GLMM which explicitly included interaction terms between time and the remaining predictors. To avoid model overparameterization, we only used the significant predictors identified in the previous analysis.

For all models, we computed the conditional predictive power $\left(R_{c}^{2}\right)$, which indicates the variance explained jointly by predictors and the random factor, and the marginal predictive power $\left(R_{m}^{2}\right)$, which only considers predictor effects. In these calculations, only significant predictors were retained in the model to avoid inflation of explained variance due to spurious parameters.

We acknowledge that it would be better to directly model the spread of SARS-CoV2, but we cannot do that without making assumptions about the relationship between infection by the virus and the appearance of symptoms of the disease, which may be related to the factors that we are investigating. All analyses were performed in R 3.6.3 ( $R$ Core Team, 2020), with aid of packages "coronabr" (Mortara et al., 2020) and "covid19br" (Paterno, 2020) for assessing counts of suspected cases by state, "Ime4" for GLMM (Bates et al., 2015), "MuMIn" for AIC and $\mathrm{R}^{2}$ calculations (Barton, 2019), and "visreg" for visualization of predictor effects (Breheny \& Bruchett, 2017).

\section{Results}

There was strong support for the model whose meteorological predictors were lagged by 15 days, as indicated by its much lower AIC (Fig. 3). According to this model, the only significant predictors of the number of confirmed COVID-19 cases were time, the number of arriving flights, population density and temperature (Table 1). The number of confirmed cases increased with time (Fig. 4a), the number of arriving flights (Fig. 4b) and population density (Fig. 4c), whereas it decreased with temperature (Fig. 4d). Considering that model coefficients were scaled, comparing their values gives an indication of the relative importance of each predictor. Accordingly, time, the number of arriving flights and population density had the strongest effects (i.e. largest coefficients), followed by temperature (Table 1). Nevertheless, a change in $1^{\circ} \mathrm{C}$ predicted a decrease in the number of confirmed cases by $[\exp (-0.26 / 3.11)-1] \times 100=8 \%$, independently of other factors (Table 1). Significant predictors explained $77 \%$ of the variance of daily counts of confirmed COVID-19 across capital cities in Brazil.

Explicitly accounting for interactions between time and the remaining predictors identified in the previous analysis suggested significant interactions between time and the number of arriving flights, and time and temperature, although the magnitude of the interaction coefficients was low (Table 2). On average, the temporal increase in confirmed COVID-19 cases began earlier in cities with more flights, causing a leftward shift in the 
201 relationship between confirmed cases and time (Fig. 5a). In parallel, the number of 202 confirmed cases increased faster at lower temperatures, causing a steeper slope in the 203 relationship between confirmed cases and time (Fig. 5b). However, these effects were 204 relatively weak, and there was no improvement in predictive power (Table 2). Thus, the 205 previous, simpler model captured the main patterns in the data very well.

206 Table 2. Results of the Generalized Linear Mixed Model (GLMM) testing for interaction 207 effects on daily cumulative counts of confirmed COVID-19 across the 27 capital cities in 208 Brazil $\left(\mathrm{n}=292 ; R_{c}^{2}=0.98 ; R_{m}^{2}=0.77\right)$. The model assumed Poisson-distributed errors 209 and log link, and used capital city identity as a random factor to account for autocorrelated 210 errors of time series within cities. Only statistically significant predictors in Table 1 were 211 used, all of which were scaled to zero mean and unit standard deviation. SD indicates 212 predictor standard deviation; numbers in bold represent statistically significant effects $(P$ 213 < 0.05). Variables were as follows: time - time elapsed in days; Log flights - log214 transformed number of arriving flights in 2020; density - inhabitants by $\mathrm{km}^{2}$; temperature 215 - mean daily temperature $\left({ }^{\circ} \mathrm{C}\right)$ with a 15 -day lag.

216

\section{Discussion}

218 Our results indicate that the number of confirmed COVID-19 cases in Brazil has 219 been higher and has begun to increase earlier in cities receiving more flights, consistent 220 with the expected role of air-transport connections in spreading the virus across the 221

222

223

224

225

226

227

228

229

230

231

232

233

234

235

236

237

238

239

240 country (Ribeiro et al., 2020, unpublished data). Further, there have been more cases in cities with higher population density, consistent with the expected role of host density (Poole, 2020). We also have uncovered a temperature response with a lag of 15 days: there have been more confirmed cases in colder cities and days, and confirmed cases have accumulated faster under lower temperature days. Although correlative, these patterns were independent of several demographic and socioeconomic factors and, thus, are unlikely to be confounded by them. This is disturbing because there is little that authorities can do about this relationship, whereas the number of arriving flights and population density can be manipulated indirectly by isolation strategies.

The temperature dependence of COVID-19 in Brazil agrees with data from China, where warmer weather also seemed to limit the spread of COVID-19 while controlling for population density and per capita GDP (Wang et al., 2020). It also agrees with the thermal dependence of viability and transmission demonstrated experimentally for better-studied viruses, such as influenza (Lowen et al., 2007) and other betacoronaviruses, e.g. SARSCoV-1 (Chan et al., 2011) and MERS-CoV (van Doremanlen et al., 2013). While the precise mechanism underlying this pattern requires further study, it may be related to the lipid bilayer of coronaviruses, which becomes increasingly unstable as temperature increases (Schoeman \& Fielding, 2019).

Recognizing that we are talking about the rate of spread and not necessarily final mortality rates, the information is still important for authorities trying to predict demands 
241 on health services. Our best estimate is that a rise of about $1{ }^{\circ} \mathrm{C}$ in mean daily temperature 242 reduces the number of COVID-19 cases by about $8 \%$, independently of other factors. 243 Thus, for instance, our results indicate that Cuiabá, with a mean July temperature of about $24423.4^{\circ} \mathrm{C}$, and Porto Alegre, with a mean July temperature of $14.9^{\circ} \mathrm{C}$, may differ up to $50 \%$ 245 in the number of COVID-19 cases, all else being equal. It also means that the spread in 246 Porto Alegre might be $41 \%$ lower in the middle of March (mean daily temperature of 21.3 $247{ }^{\circ} \mathrm{C}$ ) than it will be in the middle of July (mean daily temperature of 14.9). At the same time, 248 and contrary to some suggestions (Poole, 2020; Wang et al., 2020; Grant et al., 2020), we found no evidence for effects of solar radiation or humidity. Perhaps such conditions

250

251

252

253

254

255

256

257

258

259

260

261

262

263

264

265

266

267

268

269

270

271

272

273

274

275

276

277

278

279

280

are not limiting for the virus or the disease under the climatic conditions of Brazil. Also, rapid evolution of the climatic niche of SAR-Cov-2 could have a similar effect. Although the mutation rate of SARS-CoV seems to be moderate compared to that of other RNA viruses (Zhao et al., 2004; Yang et al., 2020), clustering of hundreds of worldwide SARSCoV-2 genomes based on widely shared polymorphisms suggests sixteen subtypes, all of which harbor amino acid replacements which may have phenotypic effects (Morais $\mathrm{Jr}$. et al., 2020, unpublished data).

Whether the temperature effect is related to the rate of spread of SARS-CoV-2 or to the proportion of persons that suffer reportable symptoms cannot be answered with the data being provided at the moment (see Fasina, 2020). That would require universal testing for the presence of the virus, which is not presently viable but may be a necessity in the following months. Also, one of the main difficulties we encountered was the lack of systematization of current information, since much of the data generated daily is still scattered and difficult to access. For instance, the number of tests performed, which is the key to estimate the rate of infection and the number of infected patients is not available. The large number of publications on the subject in the last 30 days shows that the scientific community is prepared for a quick response, as long as there is a systematization and transparency of information regarding the number of tests being performed, number of suspected cases, number of infected, number of deaths, etc.

Our models are necessarily simple and have limitations. Most importantly, we need city and state administrations to provide the number of performed tests on a regular basis, so that this variable can be explicitly accounted for in the model. The data do not allow us to investigate complex nonlinear effects, which likely would require data on temperatures beyond those observed in Brazilian cities in March. Also, it is currently not possible to account for potential interactions between COVID-19 and other diseases, particularly influenza, which is seasonal. It may not be necessary to worry about this in the northern hemisphere because the peaks in COVID-19 will occur after the peaks in seasonal influenza. However, the predicted peaks in COVID-19 in the southern hemisphere will occur concomitantly with peaks in seasonal influenza (Ne/son et al., 2006; Viboud, Alonso \& Simonsen, 2006). The effects may just be additive, but it is not known whether the simultaneous infection will increase the severity of COVID-19 and

Peer) reviewing PDF | (2020:03:47315:1:1:CHECK 26 Apr 2020) 
281 therefore the demand for ICUs, and this interaction also could be temperature sensitive. 282 Further, air pollution is known to increase susceptibility to viral respiratory infections 283 (Ciencewicki \& Jaspers, 2007), but the extent to which it affects the prevalence of COVID28419 is unclear. As COVID-19 consolidates in different cities, it will be possible to reduce

285

286

287

288

289

290

291

292

293

294

295

296

297

298

299

300

301

302

303

304

305

306

307

308

309

310

311

312

313

314

315

316

317

318

319

320 uncertainties in relation to the role of temperature and other factors. Nonetheless, our models still performed well as judged by their predictive power, even when ignoring interactions between predictors.

We stress that the temperature effect does not mean that the northern, warmer regions of Brazil should expect fewer complications in their health care system, because such regions also have poorer socioeconomic and sanitary conditions (Barreto et al., 2011), and ICUs are concentrated in southern regions (Rhodes \& Moreno, 2012). Although we found no evidence for an effect of income on the number of confirmed COVID-19 cases, this variable is related to the capacity of cities to respond to the pandemic. Furthermore, apart from elapsed time, the predictors with the largest standardized coefficients were the number of arriving flights and population density (Table 1). Indeed, Manaus, the largest city in Northern Brazil, was the first Brazilian city to declare the collapse of the health system early in April 2020, which is consistent with its large number of arriving flights and large population density but relatively low number of ICUs (Rhodes \& Moreno, 2012). By contrast, although southern, colder regions have a higher density of ICUs, their situation could be aggravated if social isolation measures are not effectively adopted before and maintained throughout winter in those regions (from June to September). This should be especially important for "favelas", i.e. poorer, highly populated neighborhoods with deficient infrastructure, which are presumably at high risk of infection. Thus, we do not present our results as an indication of how hospital demand should be calculated, but as a warning that models for Brazil need to take into account predicted temperatures.

\section{Conclusions}

Declared as a pandemic by the World Health Organization (WHO), the COVID-19 disease has changed human behavior and strongly affected health systems and the economy worldwide. In an extremely demanding scenario, optimizing the distribution of resources is an essential task. Brazil and other countries are starting to discuss the flexibilization of social distancing policies, as the latter could have important economic costs. However, we need to understand how and when to implement such decisions in order to prevent new, uncontrolled disease outbreaks that may overcrowd the health care system again and generate even higher economic costs in the near future. Our results suggest that, along with arriving flights and population density, temperature should be taken into account to estimate the number of cases of COVID-19, especially with winter approaching in the southern hemisphere. 
321 Acknowledgements

322 We are grateful to Álvaro Justen and his collaborators for compiling the daily records on 323 COVID-19 cases for Brazilian cities, and Sara Mortara, Andrea Sánchez-Tapia, Karlo 324 Martins and Gustavo Paterno for developing R packages to facilitate obtention of COVID32519 data from the Brazilian Ministry of Health. We thank the Biodiversity Research 326 Program (PPBio Brasil) of the Ministry of Science, Technology, Innovation and 327 Communication (MCTIC) of Brazil for providing the contact network that enabled quick 328 collaboration among the researchers involved in this manuscript. We also thank

329

330

331

332

333

334

335

336

337

338

339

340

341

342

343

344

345

346

347

348

349

350

351

352

353

354

355

356

357

358

359

360

Alexandre Almeida, Daniel Pimenta and Lucas Bandeira for useful suggestions on preliminary analyses, and Elizabeth Franklin, Daniela Bôlla, Fabíola Wieckert, Sérvio Ribeiro and two anonymous reviewers for useful comments on earlier versions of this manuscript. The first author received a postdoctoral fellowship from the Brazilian Agency of Higher Education (CAPES). The third and fifth authors receive a postdoctoral fellowship from the Institutional Training Program of the Brazilian National Council for Scientific and Technological Development ( $\mathrm{PCl}-\mathrm{CNPq})$. The last author receives a productivity grant from CNPq.

\section{References}

ANAC. 2020. Agência Nacional de Aviação Civil. Available at https://www.anac.gov.br/assuntos/dados-e-estatisticas/dados-estatisticos/dadosestatisticos (accessed 27 march 2020)

Anderson RM; Heesterbeek H; Klinkenberg D; Hollingsworth, TD. 2020. How will countrybased mitigation measures influence the course of the COVID-19 epidemic? The Lancet 395: 931-934 DOI: 10.1016/S0140-6736(20)30567-5

Barreto, ML; Teixeira, MG; Bastos, FI; Ximenes, RAA; Barata, RB; Rodrigues LC. 2011. Successes and failures in the control of infectious diseases in Brazil: social and environmental context, policies, interventions, and research needs. The Lancet 377 : 1877-1889 DOI 10.1016/S0140-6736(11)60202-X

Bartoń K. 2019. MuMIn: Multi-Model Inference. R Package Version 1.43.17. Available at https://CRAN.R-project.org/package=MuMIn (accessed on 16 April 2020).

Bates D; Mächler M; Bolker B; Walker S. 2015. Fitting Linear Mixed-Effects Models Using Ime4. Journal of Statistical Software 67:1-48

Breheny P, Burchett W. 2017. Visualization of Regression Models Using visreg. The $R$ Journal 9:56-71. 
361 Chan KH, Malik Peiris JS, Lam SY, Poon LLM, Yuen KY, Seto WH. 2011. The Effects of 362 Temperature and Relative Humidity on the Viability of the SARS Coronavirus. Advances 363 in Virology 2011:734690

364

365

366

367

368

369

370

371

372

373

374

375

376

377

378

379

380

381

382

383

384

385

386

387

388

389

390

391

392

393

394

395

396

397

398

399

400

Ciencewicki J; Jaspers I. 2007. Air Pollution and Respiratory Viral Infection. Inhalation Toxicology 19:1135-1146

Ebrahim SH; Ahmed QA; Gozzer E; Schlagenhauf P; Memish ZA. 2020. Covid-19 and community mitigation strategies in a pandemic. BMJ 368:m1066. DOI: 10.1136/bmj.m1066.

Fasina FO. 2020. Novel coronavirus (2019-nCoV) update: What we know and what is unknown. Asian Pacific Journal of Tropical Medicine 13:97-98 DOI: 10.1016/j.avb.2018.06.007

Ferguson NM; Laydon D; Nedjati-Gilani G; Imai N; Ainslie K; Baguelin M; Bhatia S; Boonyasiri A; Cucunubá Z; Cuomo-Dannenburg G; Dighe A; Dorigatti I; Fu H; Gaythorpe K; Green W; Hamlet A; Hinsley W; Okell LC; van Elsland S; Thompson H; Verity R; Volz E; Wang H; Wang Y; Walker PGT; Winskill P; Whittaker C; Donnelly CA; Riley S; Ghani AC. 2020. Impact of non-pharmaceutical interventions (NPIs) to reduce COVID-19 mortality and healthcare demand. Imperial College COVID-19 Response Team 1-20 DOI: $\underline{10.25561 / 77482}$

Fick SE; Hijmans RJ. 2017. WorldClim 2: new 1-km spatial resolution climate surfaces for global land areas. International Journal of Climatology 37:4302-4315. DOI: 10.1002/joc.5086

Grant WB; Lahore H; McDonnell SL; Baggerly CA; French CB; Aliano JL; Bhattoa HP. 2020. Evidence that Vitamin D Supplementation Could Reduce Risk of Influenza and COVID-19 Infections and Deaths. Nutrients 12 DOI: 10.3390/nu12040988

INMET. 2020. Estação Meteorológica de Observação de Superfície Automática. Available at http://www.inmet.gov.br/portal/index.php?r=estacoes/estacoesAutomaticas (accessed 27 march 2020)

Lauer SA; Grantz KH; Bi Q; Jones FK; Zheng Q; Meredith HR; Azman AS; Reich NG; Lessler J. 2020. The Incubation Period of Coronavirus Disease 2019 (COVID-19) From Publicly Reported Confirmed Cases: Estimation and Application. Annals Internal Medicine DOI 10.7326/M20-0504 
401 Lowen AC; Mubareka S; Steel J; Palese P. 2007. Influenza virus transmission Is 402 dependent on relative humidity and temperature. PLoS Pathogens 3: 1470-1476, e151 403 DOI: 10.1371/journal.ppat.0030151

404

405

406

407

408

409

410

411

412

413

414

415

416

417

418

419

420

421

422

423

424

425

426

427

428

429

430

431

432

433

434

435

436

437

438

Morais Jr. IJ; Polveiro RC; Souza GM; Bortolin DI; Sassaki FT; Lima ATM. 2020. The global population of SARS-CoV-2 is composed of six major subtypes. Available at https://www.biorxiv.org/content/10.1101/2020.04.14.040782v2.abstract (accessed 01 May 2020).

Mortara S; Sánchez-Tapia A; Martins KG. 2020. coronabr: Download de dados do coronavírus. R package version 0.1.0. Available at (accessed on 16 April 2020)

Nelson M; Lone Simonsen L; Viboud C; Miller MA; Taylor J; St. George K; Griesemer SB; Ghedi E; Sengamalay NA; Spiro DJ; Volkov I; Grenfell BT; Lipman DJ; Taubenberger JK; Holmes EC. 2006. Stochastic processes are key determinants of short-term evolution in influenza a virus. PLoS Pathogens 2:e125. DOI: 10.1371/journal.ppat. 0020125.

Paterno GB. 2020. covid19br: An r-package with updated data on the number of coronavirus (covid-19) cases in Brazil. Available at https://doi.org/10.17605/OSF.IO/ZS4HT (accessed on 16 April 2020).

Poole, L. 2020. Seasonal influences on the spread of SARS-CoV-2 (COVID19), causality, and forecastabililty (3-15-2020). Available at SSRN: http://dx.doi.org/10.2139/ssrn.3554746

R Core Team. 2020. R: A language and environment for statistical computing. Vienna, Austria: R Foundation for Statistical Computing.

Rhodes A; Moreno RP. 2012. Intensive care provision: a global problem. Revista Brasileira de Terapia Intensiva 24:322-325 DOI: 10.1590/S0103-507X2012000400005

Ribeiro SP; Dattilo W; Castro e Silva A; Reis AB; Goes-Neto A; Alcantara L; Giovanetti M; Couravital W; Fernandes GW; Azevedo VA. 2020. Severe airport sanitarian control could slow down the spreading of COVID-19 pandemics in Brazil. Available at https://www.medrxiv.org/content/10.1101/2020.03.26.20044370v2 (accessed 01 May 2020).

Roser M, Ritchie H, Ortiz-Ospina E, Hasell J. 2020. Coronavirus Disease (COVID-19) Statistics and Research. Available at https://ourworldindata.org/coronavirus (Accessed 16 April 2020) 
439

440

441

442

443

444

445

446

447

448

449

450

451

452

453

454

455

456

457

458

459

460

461

462

463

464

465

466

467

468

469

470

471

472

473

474

475

476

477

478

Sajadi MM; Habibzadeh P; Vintzileos A; Shokouhi S; Miralles-Wilhelm F; Amoroso A. 2020. Temperature, humidity, and latitude analysis to predict potential spread and seasonality for COVID-19 Available at SSRN: https://ssrn.com/abstract $=3550308$

Scheffer M,Cassenote A, Guilloux AGA, Biancarelli A, Miotto BA, Mainardi GM. 2018. Demografia Médica no Brasil 2018. São Paulo: FMUSP. 286 p.

Secretarias de Saúde das Unidades Federativas. 2020. Dados diários mais recentes do coronavírus por município brasileiro. Data processed by Álvaro Justen/Brasil.io. Available at https://blog.brasil.io/2020/03/23/dados-coronavirus-por-municipio-mais-atualizados/ (accessed 26 march 2020)

Schoeman D, Fielding BC. 2019. Coronavirus envelope protein: current knowledge. Virology Journal 16:69

Sidra. 2020. Pesquisa Nacional por Amostra de Domicílios Contínua Trimestral: Tabela 5918 - População por grupo de idade. Available at https://sidra.ibge.gov.br/tabela/5918 (accessed 27 march 2020)

van Doremalen N, Bushmaker T, Munster VJ. 2013. Stability of Middle East respiratory syndrome coronavirus (MERS-CoV) under different environmental conditions. Eurosurveillance 18: 20590

Viboud C; Alonso WJ; Simonsen L. 2006a Influenza in tropical regions. PLoS Med 3:e89 DOI: 10.1371/journal. pmed.0030089.

Xu, Z., Shi, L., Wang, Y., Zhang, J., Huang, L., Zhang, C., Liu, S., Zhao, P., Liu, H., Zhu, L. and Tai, Y., 2020. Pathological findings of COVID-19 associated with acute respiratory distress syndrome. The Lancet Respiratory Medicine. DOI: 10.1016/S22132600(20)30076-X

Walker PGT; Whittaker C; Watson O; Baguelin M; Ainslie KEC; Bhatia S; Bhatt S; Boonyasiri A; Boyd O; Cattarino L; Cucunubá Z; Cuomo-Dannenburg G; Dighe A; Donnelly CA; Dorigatti I; van Elsland S; FitzJohn R; Flaxman S; Fu H; Gaythorpe K; Geidelberg L; Grassly N; Green W; Hamlet A; Hauck K; Haw D; Hayes S; Hinsley W; Imai N; Jorgensen D; Knock E; Laydon D; Mishra S; Nedjati-Gilani G; Okell LC; Riley S; Thompson H; Unwin J; Verity R; Vollmer M; Walters C; Wang HW; Wang Y; Winskill P; Xi X; Ferguson NM; Ghani AC. 2020. The Global Impact of COVID-19 and Strategies for Mitigation and Suppression. Imperial College COVID-19 Response Team 1-19. 
479

480 Wang J; Tang K; Feng K; Lv W. 2020. High temperature and high humidity reduce the 481

482

483

484

485

486

487

488

489

490

491

492

493

494

495

496

transmission of COVID-19. Available at SSRN: https://ssrn.com/abstract=3551767

Wilder-Smith A.; Freedman DO. 2020. Isolation, quarantine, social distancing and community containment: pivotal role for old-style public health measures in the novel coronavirus (2019-nCoV) outbreak. Journal of Travel Medicine DOI 10.1093/jtm/taaa020

Yang Y; Peng F; Wang R; Guan K; Jiang T; Xu G; Sun J; Chang C. 2020. The deadly coronaviruses: The 2003 SARS pandemic and the 2020 novel coronavirus epidemic in China. Journal of Autoimmunity 102434 DOI: 10.1016/j.jaut.2020

Zhao Z; Li H; Wu X; Zhong Y; Zhang K; Zhang Y; Boerwinkle E; Fu Y. 2004. Moderate mutation rate in the SARS coronavirus genome and its implications. BMC Evolutionary Biology 4:21. DOI: 10.1186/1471-2148-4-21

Zuur AF; leno EN; Walker NJ; Saveliev AA; Smith GM. 2009. Mixed effects models and extensions in ecology with $R$. Springer. 


\section{Table $\mathbf{1}$ (on next page)}

Results of the Generalized Linear Mixed Model (GLMM) for daily counts of confirmed COVID-19 across state capital cities in Brazil.

Table 1. Results of the most supported Generalized Linear Mixed Model (GLMM) for daily counts of confirmed COVID-19 across state capital cities in Brazil $(n=298)$. The model assumed Poisson-distributed errors and log link, and used capital city identity as a random factor to account for autocorrelated errors of time series within cities. All predictors were scaled to zero mean and unit standard deviation. Numbers in parentheses indicate predictor standard deviations; numbers in bold represent statistically significant effects $(P<0.05)$. Variables were as follows: time - time elapsed in days; density - inhabitants by $\mathrm{km}^{2}$; elders number of elders ( $\geq 60$ years old) per 1000 citizens; physicians - number of registered physicians per 1000 citizens; income - mean citizen income (R\$); flights - number of arriving flights in 2020; temperature - mean daily temperature (으) with a 15-day lag; radiation mean daily solar radiation $\left(\mathrm{kJ} / \mathrm{m}^{2}\right)$ with a 15 -day lag. 
1 Table 1. Results of the most supported Generalized Linear Mixed Model (GLMM) testing 2 for independent effects on daily cumulative counts of confirmed COVID-19 across the 27 3 capital cities in Brazil $\left(\mathrm{n}=292 ; R_{c}^{2}=0.98 ; R_{m}^{2}=0.77\right.$ ). The model assumed Poisson4 distributed errors and log link, and used capital city identity as a random factor to account 5 for autocorrelated errors of time series within cities. All predictors were scaled to zero 6 mean and unit standard deviation. SD indicates predictor standard deviation; numbers in 7 bold represent statistically significant effects $(P<0.05)$. Variables were as follows: time 8 time elapsed in days; Log suspected - log-transformed number of suspected COVID-19 9 cases in March 18, 2020; Log flights - log-transformed number of arriving flights in 2020; 10 density - inhabitants by $\mathrm{km}^{2}$; elderly - proportion of elderly people ( $\geq 60$ years old); income 11 - mean citizen income $(\mathrm{R} \$)$; temperature - mean daily temperature $\left({ }^{\circ} \mathrm{C}\right)$ with a 15 -day lag; 12 radiation - mean daily solar radiation $\left(\mathrm{kJ} / \mathrm{m}^{2}\right)$ with a 15 -day lag; humidity - mean daily air 13 humidity (\%) with a 15-day lag.

\begin{tabular}{|c|c|c|c|c|}
\hline Predictor & SD & Coefficient & z & \\
\hline Intercept & - & 2.17 & - & - \\
\hline Time & 5.72 & 1.4 & 67.7 & $<0.001$ \\
\hline Log suspected & 1399.23 & 0.18 & 0.59 & 0.556 \\
\hline Log flights & 351.06 & 0.86 & 3.2 & 0.001 \\
\hline Density & 3087.94 & 0.47 & 2.01 & 0.044 \\
\hline Elderly & 3.6 & -0.36 & -1.59 & 0.111 \\
\hline Income & 787.39 & 0.17 & 0.81 & 0.415 \\
\hline Temperature & 3.11 & -0.26 & -5.87 & $<0.001$ \\
\hline
\end{tabular}


Radiation

Humidity
321.67

10.26
0.04

0.07
$1.52 \quad 0.127$

$1.74 \quad 0.082$

14 


\section{Table 2 (on next page)}

Results of the Generalized Linear Mixed Model (GLMM) testing for interaction effects on daily cumulative counts of confirmed COVID-19 in Brazil

Table 2. Results of the Generalized Linear Mixed Model (GLMM) testing for interaction effects on daily cumulative counts of confirmed COVID-19 across the 27 capital cities in Brazil $(n=$ 292; $\left.R_{c}^{2}=0.98 ; R_{m}^{2}=0.77\right)$. The model assumed Poisson-distributed errors and log link, and used capital city identity as a random factor to account for autocorrelated errors of time series within cities. Only statistically significant predictors in Table 1 were used, all of which were scaled to zero mean and unit standard deviation. SD indicates predictor standard deviation; numbers in bold represent statistically significant effects $(P<0.05)$. Variables were as follows: time - time elapsed in days; Log flights - log-transformed number of arriving flights in 2020; density - inhabitants by $\mathrm{km}^{2}$; temperature - mean daily temperature $(\stackrel{\circ}{ } \mathrm{C})$ with a 15-day lag. 
1 Table 2. Results of the Generalized Linear Mixed Model (GLMM) testing for interaction 2 effects on daily cumulative counts of confirmed COVID-19 across the 27 capital cities in 3 Brazil $\left(\mathrm{n}=292 ; R_{c}^{2}=0.98 ; R_{m}^{2}=0.77\right)$. The model assumed Poisson-distributed errors 4 and log link, and used capital city identity as a random factor to account for autocorrelated 5 errors of time series within cities. Only statistically significant predictors in Table 1 were 6 used, all of which were scaled to zero mean and unit standard deviation. SD indicates 7 predictor standard deviation; numbers in bold represent statistically significant effects $(P$ $8<0.05)$. Variables were as follows: time - time elapsed in days; Log flights - log9 transformed number of arriving flights in 2020; density - inhabitants by $\mathrm{km}^{2}$; temperature 10 - mean daily temperature $\left({ }^{\circ} \mathrm{C}\right)$ with a 15 -day lag.

\begin{tabular}{lllll} 
Predictor & SD & Coefficient & z & P \\
\hline Intercept & - & 2.13 & - & - \\
Time & 5.71 & 1.45 & 46.55 & $<0.001$ \\
Log flights & 1.19 & 0.96 & 4.67 & $<0.001$ \\
Density & 3057.46 & 0.31 & 1.58 & 0.115 \\
Temperature & 3.11 & -0.30 & -8.91 & $<0.001$ \\
Time $\times$ log flights & - & -0.08 & -2.46 & $\mathbf{0 . 0 1 4}$ \\
Time $\times$ density & - & 0.01 & 0.47 & 0.641 \\
Time $\times$ temperature & - & -0.08 & -2.85 & $\mathbf{0 . 0 0 4}$ \\
\hline
\end{tabular}


Figure 1

Confirmed COVID-19 cases across capital cities in Brazil

Fig. 1. Distribution of counts of confirmed COVID-19 cases across capital cities in Brazil on 26 March, $2020(n=27)$, superimposed on the country's thermal variability. Temperature data represent means for March over 1998-2018. 


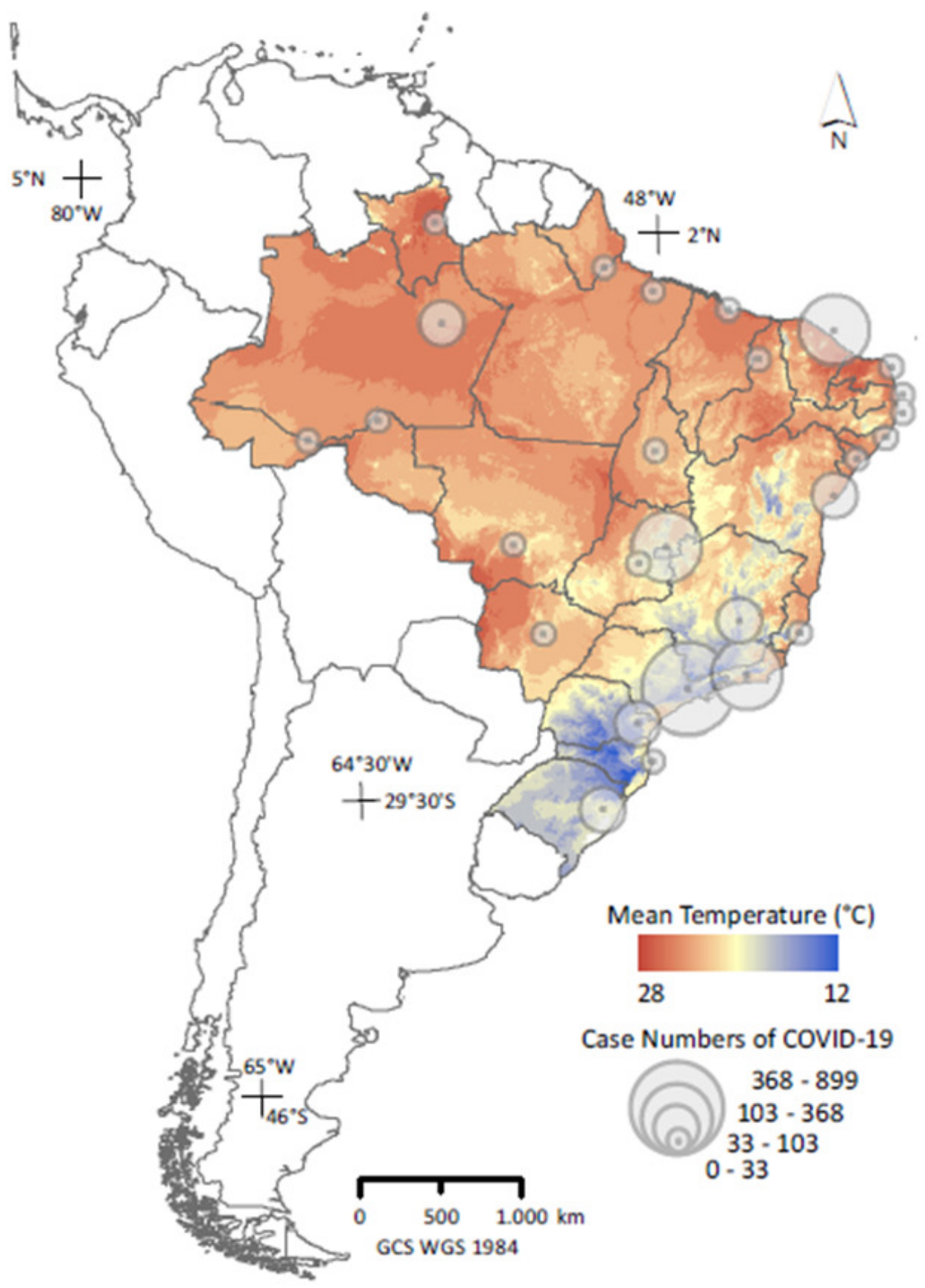


Figure 2

Daily counts of confirmed cases of COVID-2019 across Brazilian state capital cities during the first month

Fig. 2. Exponential increase in daily counts of confirmed cases of COVID-2019 across Brazilian state capital cities $(n=298)$ during the first monitored month. Each line/colour represents one capital city $(n=27)$. 


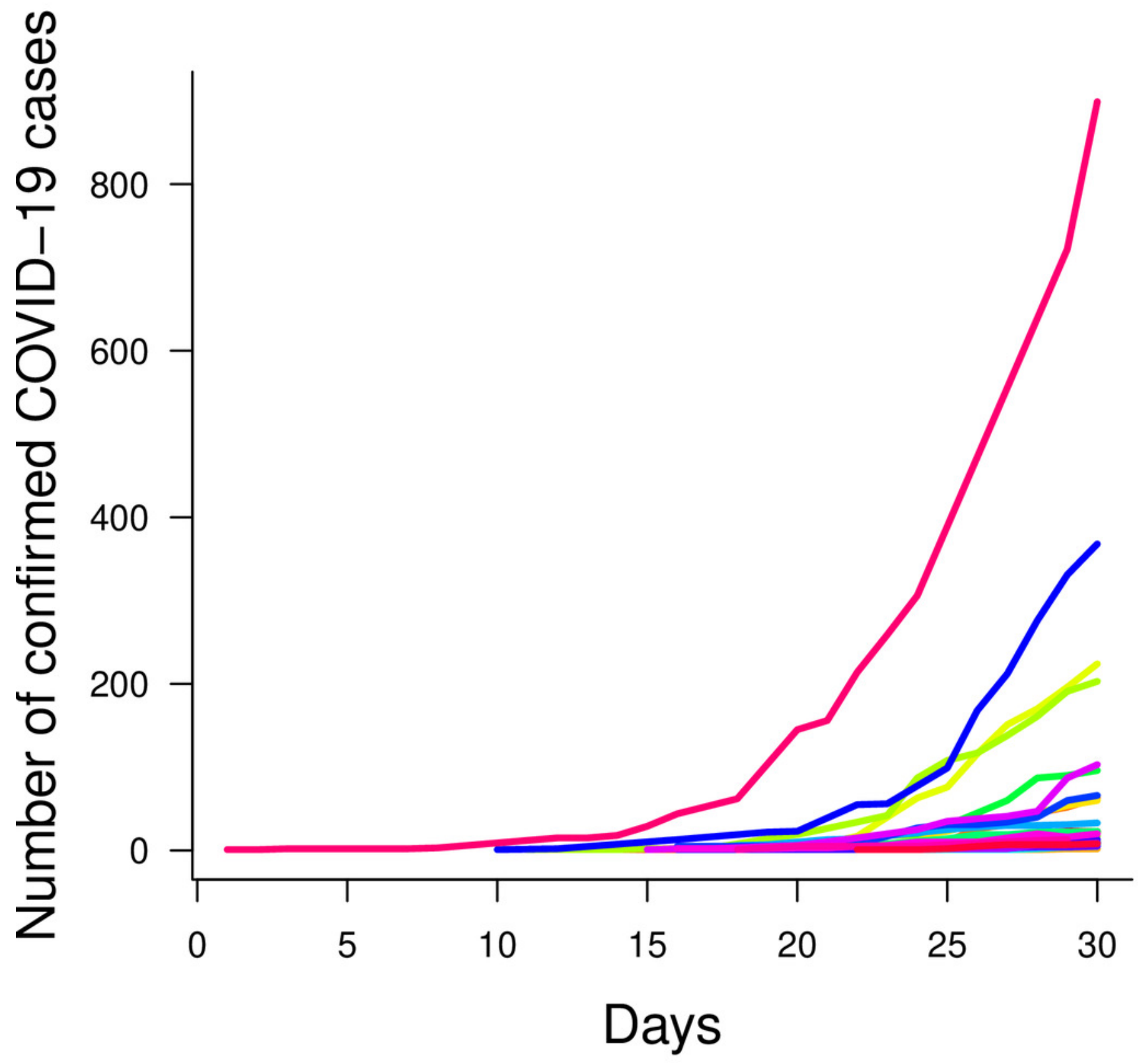


Figure 3

Models considering different time lags in meteorological predictors

Fig. 3. Comparison of models considering different time lags in meteorological predictors using Akaike's Information Criterion (AIC). Each point represents one alternative model 


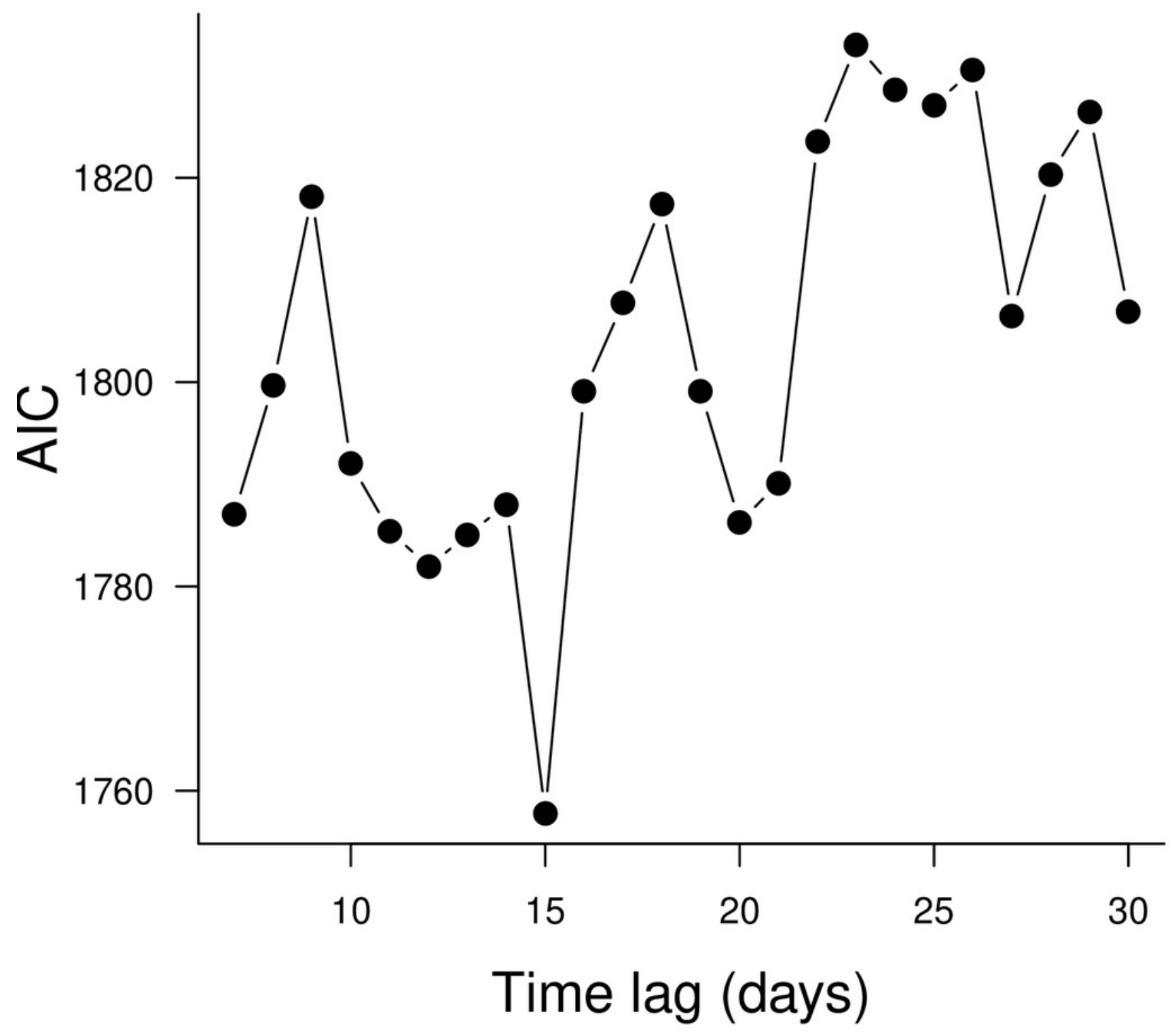




\section{Figure 4}

Response of daily counts of confirmed COVID-19 cases across Brazilian capital cities.

Fig. 4 Response of daily counts of confirmed COVID-19 cases across Brazilian capital cities to (a) time, (b) population density, (c) number of arriving flights and (d) temperature, as indicated by the most supported Generalized Linear Mixed Model (GLMM). The model assumed Poisson-distributed errors and log link, and included capital city identity as a random factor to account for autocorrelated errors in time series within cities. Each point represents a daily observation in a given city $(n=298)$; lines represent predicted means. Plots use partial residuals of the response variable and thus show the effect of a given predictor while controlling the effects of remaining predictors. 
(a)

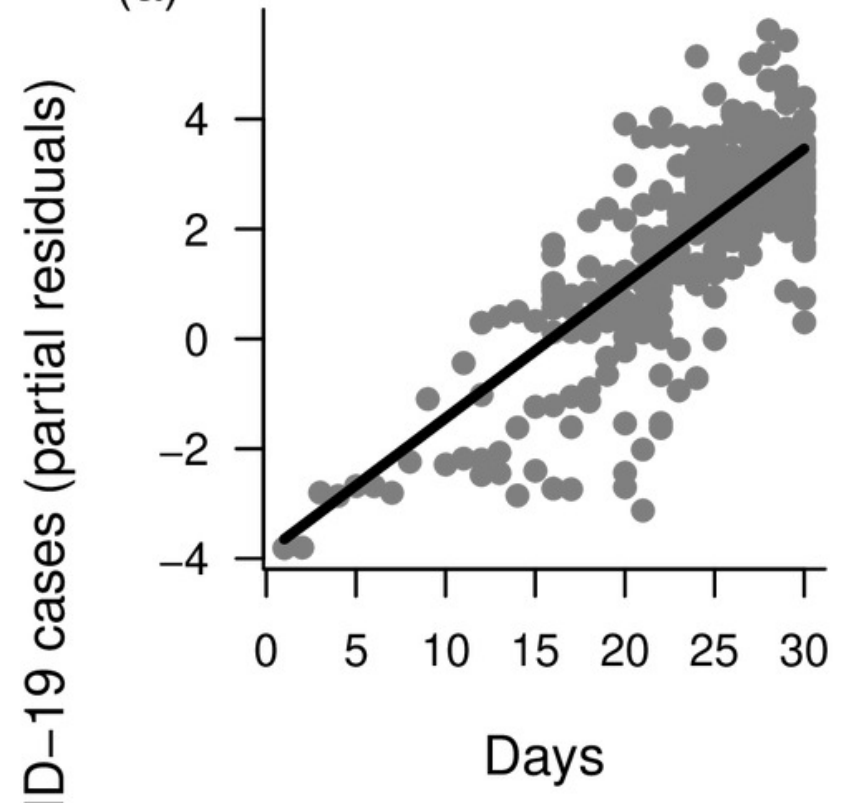

(c)

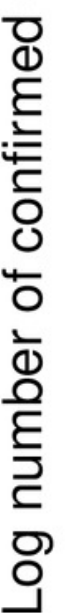

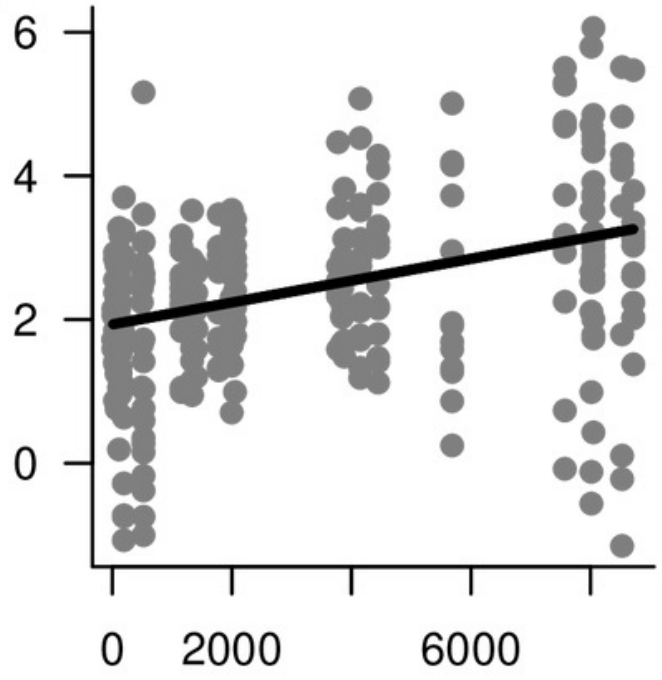

Inhabitants per km² (b)

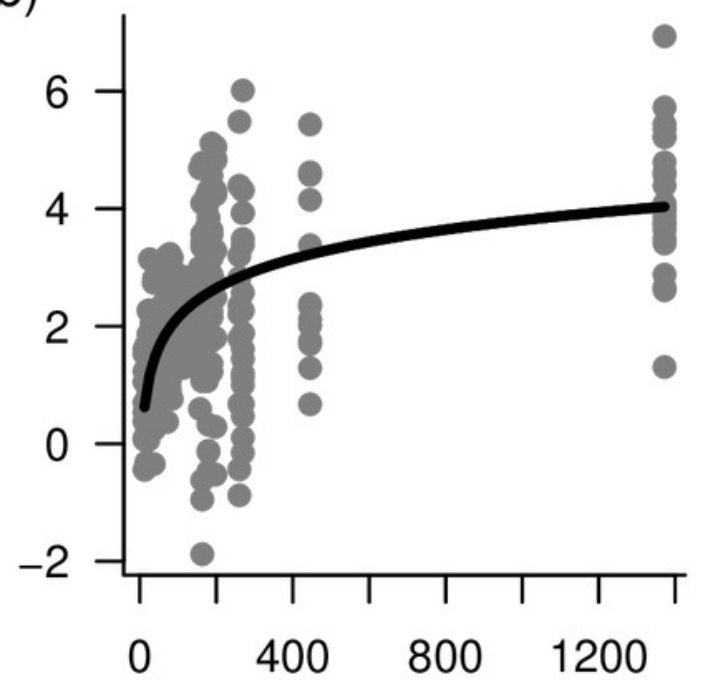

Number of arriving flights

(d)

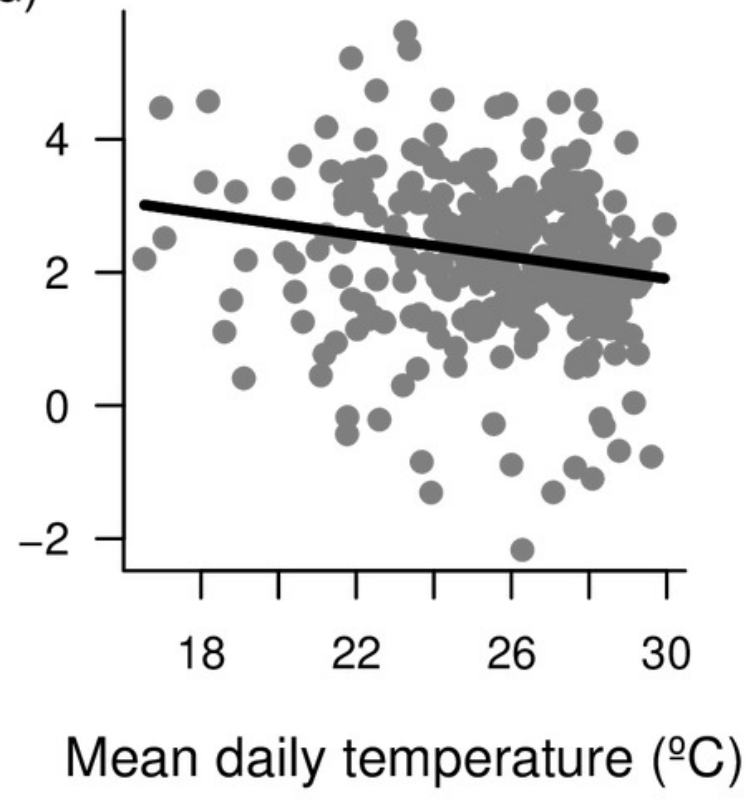




\section{Table 3 (on next page)}

Response of daily cumulative counts of confirmed COVID-19 cases in Brazil to interactive effects between time an number of arriving flights and mean daily temperature.

Fig. 5 Response of daily cumulative counts of confirmed COVID-19 cases across the 27 Brazilian capital cities to interactive effects of (a) time and number of arriving flights, and (b) time and mean daily temperature, based on the Generalized Linear Mixed Model (GLMM) presented in Table 2. The model assumed Poisson-distributed errors and log link, and included capital city identity as a random factor to account for autocorrelated errors in time series within cities. Each point represents a daily observation in a given city $(n=292)$; lines represent predicted means for each group of observations, as indicated by legends. Group medians were chosen based on their respective predictor ranges (see Fig. 4). Plots use partial residuals of the response variable and thus show the effect of a given interaction while controlling the effects of remaining predictors. 


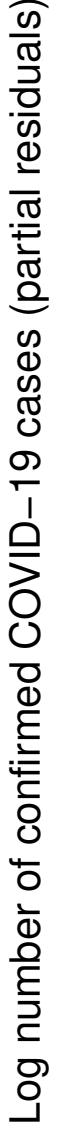

(a)

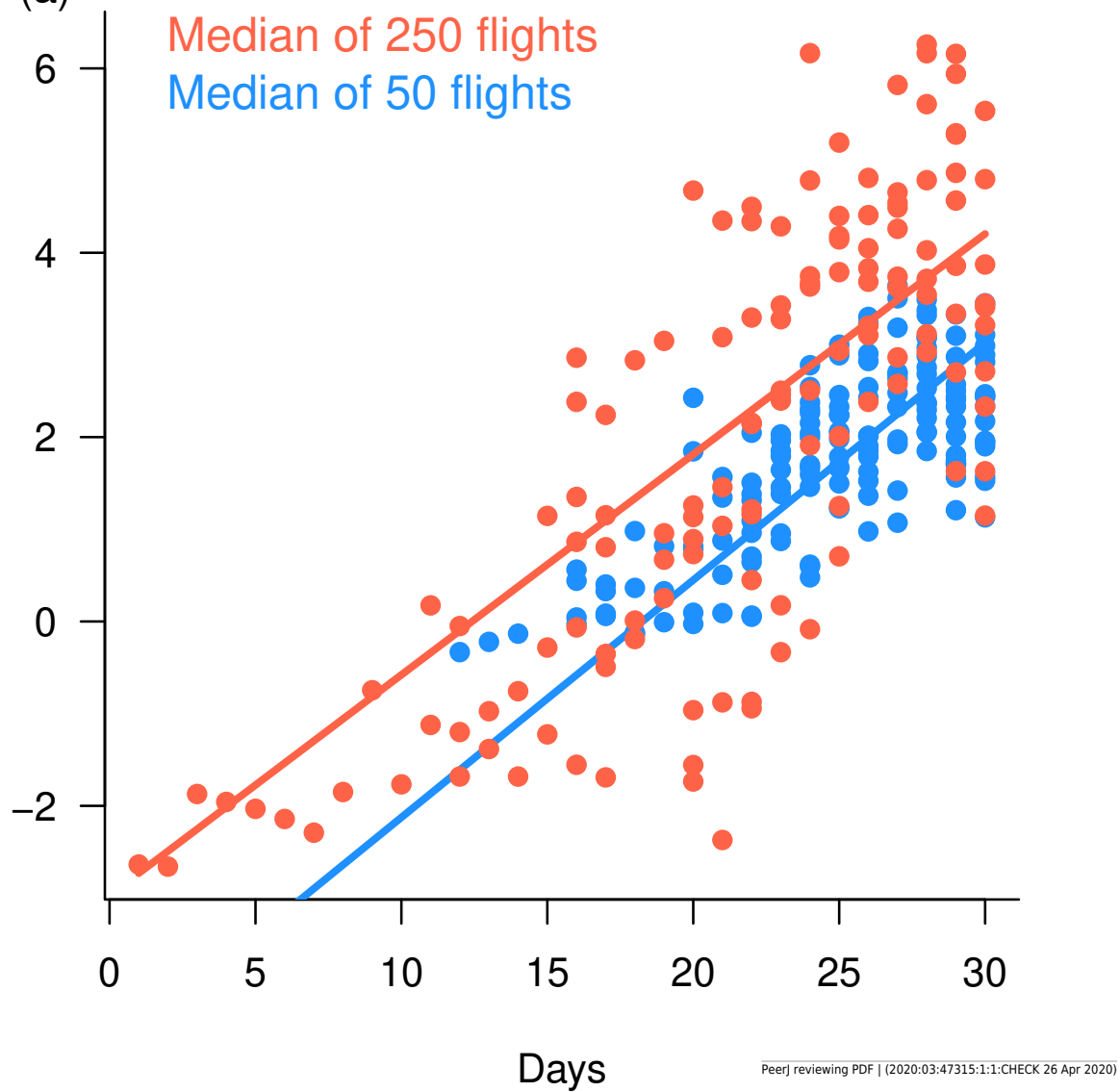

Manuscript to be reviewed

(b)

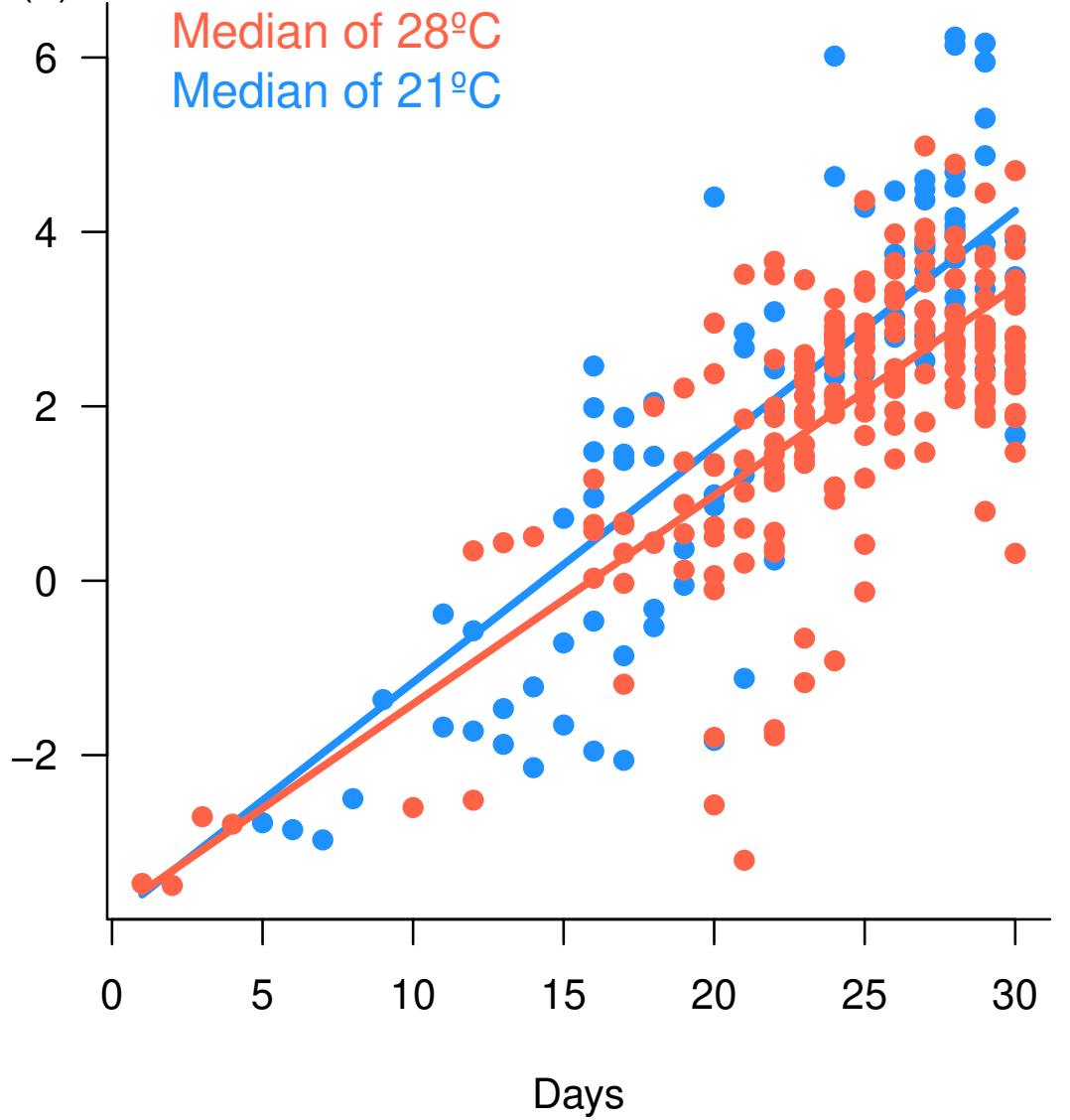

